\title{
Citrus limon, Melaleuca alternifolia E Psidium guajava COMO INIBIDORES NATURAIS DE Sporothrix schenckii
}

\author{
Citrus limon, Melaleuca alternifolia AND Psidium guajava AS NATURAL \\ INHIBITORS OF Sporothrix schenckii
}

\author{
Júlio Róger Evangelista dos Santos ${ }^{1}$, Marisa Cristina da Fonseca Casteluber ${ }^{1 *}$ \\ ${ }^{1}$ Universidade do Estado de Minas Gerais, Ibirité, MG, Brasil. \\ *Autor de correspondência: marisa.casteluber@uemg.br
}

Recebido: 03 de abril de 2020; Aceito: 08 de outubro de 2020.

\section{RESUMO}

A esporotricose é uma micose subcutânea, de caráter crônico, que pode acometer animais, como cães e gatos e em menor frequência os seres humanos. $\mathrm{O}$ agente etiológico pertence ao complexo Sporothrix schenckii. O tratamento para esta infecção, com os medicamentos atualmente disponíveis, é longo e muitas vezes ineficaz por falta de adesão à medicação de escolha ou até mesmo por resistência do fungo aos antifúngicos disponíveis. O objetivo deste estudo foi analisar in vitro o potencial do óleo essencial de Citrus limon, do óleo essencial de Melaleuca alternifolia e do extrato da folha de Psidium guajava como fármacos naturais para inibição do crescimento de Sporothrix schenckii e por fim comparar a eficácia desses substratos naturais com o antifúngico sintético mais utilizado no tratamento da doença, o itraconazol. Os métodos utilizados na pesquisa foram o de disco difusão em ágar e o ensaio da concentração inibitória mínima (CIM). Os testes realizados demonstraram que os óleos essenciais e o extrato estudado foram eficientes para inibir o crescimento fúngico superando até mesmo o itraconazol, utilizado como controle experimental. Os dados obtidos permitem sugerir que os óleos essenciais e o extrato testados podem ser utilizados como tratamento alternativo ou possivelmente para complementar o tratamento convencional, sendo necessários mais estudos in vivo para confirmar essa afirmação. Os resultados aqui obtidos são relevantes para futuras utilizações desses biofármacos para o tratamento da esporotricose que tem se tornado cada vez mais frequente em felinos em Belo Horizonte e região metropolitana.

Palavras-chave: Antifúngicos. Esporotricose. Óleos Essenciais. Resistência Fúngica.

\section{ABSTRACT}

The sporotrichosis is a chronic, subcutaneous mycosis that can affect animals, such as dogs and cats and with less frequency in humans. The etiologic agent belongs to the Sporothrix schenckii complex. The treatment for this infection, with currently available medications, is long and often ineffective due to lack of adherence to the medication of choice or even due to the fungus resistance to available antifungals. The objective of this study was to analyze in vitro the 
potential of Citrus limon essential oil, Melaleuca alternifolia essential oil and Psidium guajava leaf extract as natural drugs to inhibit the growth of Sporothrix schenckii and finally to compare the effectiveness of these oils with the most widely used synthetic antifungal in the treatment of the disease, itraconazole. The methods used in the research were the disc diffusion assay and the minimum inhibitory concentration (MIC) assay. The tests carried out demonstrated that the essential oils and the studied extract were efficient to inhibit the fungal growth surpassing even itraconazole, used as a positive control. The data obtained allow us to suggest that the tested essential oils and extract can be used as an alternative treatment or possibly to complement conventional treatment, and further in vivo studies are needed to confirm this statement. The results obtained here are relevant for future uses of these biopharmaceuticals for the treatment of sporotrichosis, which has become increasingly frequent in felines in Belo Horizonte and the metropolitan region.

Keywords: Antifungals. Sporotrichosis. Essential Oils. Fungal resistance.

\section{INTRODUÇÃO}

Os fungos são organismos eucariotos, quimio-heterotróficos, apresentam parede celular quitinosa e rígida, podem ser multicelulares, formando micélio vegetativo constituído por hifas ou serem leveduriformes possuindo apenas uma célula e neste caso nominados unicelulares (ALEXOPOULOS et al., 1996). Eles podem atuar como sapróbios, realizando a decomposição de matéria orgânica morta, o que é extremamente relevante ao ecossistema. Além disso, podem ser também considerados parasitos de animais ou plantas quando se nutrem desses hospedeiros vivos (TORTORA; CASE; FUNKE, 2017).

Os fungos são utilizados como alimentos pelos seres humanos desde eras muito antigas, podendo ressaltar o consumo de cogumelos do tipo champignon, o shitake, e também a utilização da levedura Saccharomyces cerevisiae para a fermentação e fabricação de pães, vinhos, cerveja e na indústria farmacêutica para a produção de antibióticos, como é o caso da penicilina, primeiro antibiótico descrito e ainda utilizado para combater infecções bacterianas (TORTORA; CASE; FUNKE, 2017).

Neste trabalho o fungo em estudo foi o Sporothrix schenckii, agente etiológico da esporotricose. Esse fungo compõe complexo Sporothrix schenckii que agrupa espécies de fungos dimórficos, patogênicos, geralmente presentes no solo, crescendo em plantas, cascas de árvores e material em decomposição, estando preferencialmente em ambientes tropicais e úmidos (NUNES; ESCOSTEGUY, 2005). É proposto que existam ao menos seis espécies nesse complexo, sendo elas: S. schenckii, S. brasilienses, S. globosa, S. mexicana, $S$. albicans e $S$. Iuriei, destacando-se o Sporothrix brasiliensis que é recorrente e endêmico do território brasileiro. O complexo é integrante da Divisão Ascomycota, da Classe Sordariomycetes, Ordem Ophiostomatales e Família Ophiostomataceae (GUARRO et al., 1999). O Sporothrix schenckii, é um fungo saprófito com distribuição geográfica mundial $e$ aspectos micro $e$ macromorfológicos distintos conforme a temperatura, podendo apresentar a forma micelial em temperaturas em torno de $25^{\circ} \mathrm{C}$ e leveduriforme quando 
cultivado em temperatura corpórea, em torno de $37^{\circ} \mathrm{C}$. Esse fungo produz melanina, como substância de proteção contra a fagocitose pelos macrófagos e ação de proteínas extracelulares (RIPPON, 1988; BRUM et al., 2007).

A esporotricose, também conhecida popularmente como "doença do jardineiro", é uma micose subcutânea que acomete animais e em menor frequência, o ser humano. A disseminação da doença é mundial, ocorrendo particularmente em áreas tropicais e subtropicais, como o Brasil, onde a incidência da esporotricose contraída pelo contato com gatos contaminados vem aumentando (NUNES; ESCOSTEGUY, 2005). Muitos casos têm sido reportados no Rio de Janeiro e em outros estados do Brasil, como Minas Gerais, Espírito Santo, São Paulo, Paraná e Rio Grande do Sul (MACEDO-SALES et al., 2019).

A transmissão do fungo ao ser humano ocorre por mordidas e arranhões de gatos infectados, ou ainda pelo contato da pele ou mucosa com as secreções das lesões e mais raramente por inalação do Sporothrix schenckii em sua forma filamentosa, presente no ambiente. Na maior parte dos casos o quadro clínico de esporotricose evolui como enfermidade moderada, restrita apenas à pele, ao tecido celular subcutâneo e vasos linfáticos adjacentes, mas ocasionalmente pode se alastrar, afetando o sistema esquelético e alguns órgãos internos. As formas clínicas são classificadas em cutânea fixa ou localizada, cutâneolinfática, cutânea disseminada, mucosa e extra cutânea ou sistêmica (NELSON; COUTO, 2006; RAMOS-E-SILVA et al., 2007).

O medicamento comumente utilizado para tratamento da esporotricose tanto em humanos como em felinos é o itraconazol, um composto triazólico que age alterando a permeabilidade celular. Outras opções de fármacos para o tratamento são fluconazol, terbinafina e anfoterecina $B$, ou ressecção cirúrgica das lesões. O tratamento de felinos com itraconazol é efetuado na dose $10 \mathrm{mg} . \mathrm{kg}^{-1}$ por dia, podendo ser dado uma vez ao dia ou dividido em doses de $5 \mathrm{mg} / \mathrm{kg}$ duas vezes ao dia, por via oral, preferencialmente junto com comida, por até um mês após melhora dos sintomas (LLORET et al., 2013).

Antifúngicos, também chamados de antimicóticos, são medicamentos fungicidas ou fungistáticos com finalidade profilática e terapêutica. O antifúngico ideal para o tratamento deve possuir amplo espectro de ação, não ser alérgeno, possuir toxicidade seletiva, ou seja, ser eficaz sem causar efeitos colaterais adversos, ter baixo custo e não permitir seleção de amostras resistentes, consequentemente, se torna complexo criar um medicamento com tais potenciais de ação em conjunto (MOREIRA et al., 2017). Os critérios para desenvolver um antimicrobiano que ataque células eucariontes, como é o caso dos fungos, são mais complexos e difíceis do que um fármaco que afete células procariontes e isso se deve às semelhanças com as células humanas, aumentando ainda mais os critérios para o desenvolvimento de um agente antifúngico que possua potenciais de ação apenas contra o fungo (MADIGAN et al., 2015).

Atualmente, os poliênicos, como a anfotericina B e os azóis, destacandose o itraconazol, vem sendo os fármacos de primeira escolha nos tratamentos antifúngicos. Os poliênicos agem na membrana celular dos fungos, onde os polienos ligam-se ao ergosterol, formando poros na membrana, o que ocasiona um aumento na permeabilidade da membrana permitindo o extravasamento de moléculas, levando à morte celular (BERGOLD; GEORGIADIS, 2004). Já os 
derivados azólicos atuam na inibição da esterol-14-a-desmetilase, impedindo a síntese do ergosterol na membrana citoplasmática e acarretando o acúmulo de 14-a-metilesteróis, isso faz com que haja formação da membrana com propriedades alteradas, não desempenhando as funções fundamentais para o desenvolvimento do fungo. Embora a classe dos azóis causem menos efeitos colaterais que a anfotericina $\mathrm{B}$, eles apresentam mecanismos menos potentes que a classe dos poliênicos. A utilização com maior frequência dos medicamentos da classe dos azóis como o Itraconazol, ocasionou o aparecimento de resistência em espécies capazes de sofrer modificações (BERGOLD; GEORGIADIS, 2004).

O itraconazol ainda é o fármaco mais utilizado para tratamento das formas cutâneas e linfocutâneas das micoses humanas e, em consequência de seu uso desordenado, apresentam-se constantes relatos de fungos resistentes ao fármaco, resultando em falhas no tratamento da micose tanto nos seres humanos quanto nos animais. Além disso doses elevadas podem gerar efeitos tóxicos para o feto, por ser teratogênico. Também causam diminuição do apetite, perda de peso, vômitos e diarreia em felinos. Podem aparecer outros efeitos colaterais tanto em humanos quanto em felinos, causando icterícia por problemas hepáticos (MEINERZ et al., 2007; PIMENTEL et al., 2017; COSTA, 2019).

Essa resistência, e muitas vezes a ineficácia do itraconazol no combate à esporotricose, seja por abandono do tratamento ou por utilização errada da medicação, apontam a necessidade de buscar outras alternativas para conter a crescente infecção desse fungo no país. Uma dessas alternativas pode ser a utilização de plantas medicinais, utilizadas há seculos no país pelos saberes tradicionais das comunidades que vem sendo passados de geração a geração, utilizando-as como medida para tratamento. Mesmo com o desenvolvimento tecnológico e de diversos fármacos, parte da população brasileira ainda utiliza as plantas como medida medicamentosa, isso se deve a fatores como baixa renda da população e o custo elevado dos medicamentos fazendo com que a prática do consumo de fitoterápicos persista e muitas vezes ressalte conhecimentos empíricos que foram presentes em nossa história por longos anos na tradição oral até mesmo sem a comprovação científica (BARROS et al., 2019).

As pesquisas realizadas recentemente com plantas medicinais no Brasil envolvem inúmeras áreas como a etnobotânica, a etnofarmacologia e a farmacologia, as quais tem contribuido para o conhecimento dos princípios ativos e essencialmente da atividade biológica de plantas existentes nos diferentes biomas brasileiros (SOUZA, 2016). O conhecimento popular sobre a utilização e a efetividade de plantas medicinais colaboram de forma significativa para difundir os saberes das propriedades terapêuticas das plantas e também desencadeia a curiosidade de pesquisadores das áreas anteriormente citadas, fazendo com que se amplie o conhecimento das potencialidades medicamentosas e impulsionando a utilização de fitoterápicos (STEFANELLO et al., 2018). Neste estudo foram testados dois óleos essenciais: o óleo de Citrus limon, o óleo de Melaleuca alternifolia e um extrato de panta, o extrato de Psidium guajava para verificar a eficácia como inibidores do crescimento de Sporothrix schenckii in vitro. 
O gênero Citrus apresenta diversas espécies no Brasil, o Citrus limon (limão siciliano), é uma árvore perenifólia e de fácil cultivo, pertencente à família Rutaceae, possuindo folhas unifolioladas de cor verde, formato lanceolada, ponta obtusa e margem serreada, tendo sua origem nativa da região sudeste da Ásia, seu fruto apresenta a cor amarela em seu período de maturação, casca grossa e superfície moderadamente rugosa. Possui atividade anticancerígena, potencial antibacteriano, presenças de compostos fenólicos e antioxidantes naturais (OJASTI et al., 2001; EVERTON et al., 2018). No Brasil, o limão é utilizado popularmente por apresentar eficácia no tratamento de infecções, febres, acidez no estômago e por apresentar potencialidades antimicrobianas, anti-inflamatória, antiparasitária e antiséptica (MARTINS et al., 2018). Na casca do limão é possível extrair um óleo essencial que tem como principal constituinte o limoneno e o citral, que apresentam atividade antimicrobiana comprovadas em estudos sobre as bactérias Escherichia coli e Staphylococcus aureus (MISHARINA; SAMUSENKO; SCHUCK et al., apud SANTOS et al., 2011). Apesar dos resultados observados da eficácia do limão siciliano contra alguns microrganismos, ainda não foram descritos estudos sobre a eficácia desse óleo essencial como inibidor do crescimento de Sporothrix schenckii. Em virtude disto, o presente trabalho é pioneiro em propor a utilização do óleo essencial do limão siciliano para o controle do crescimento de $S$. schenckii.

A Melaleuca alternifolia, também conhecida como árvore-do-chá, é uma árvore aromática, de casca fina e com folhas simples, coriáceas e de formato lanceolada ou de foice. Pertencente à família Myrtaceae, com origem nativa da Austrália, possui vasto interesse econômico em virtude da presença de óleo volátil armazenado em seu tecido foliar. A composição química do óleo essencial do tecido foliar de $M$. alternifolia é rica em terpinen-4-ol, sendo esse composto responsável por suas potencialidades medicinais, especialmente antimicrobianas (MARTINS et al., 2011; SILVA, 2018). Já foram descritas pesquisas utilizando o óleo de melaleuca in vitro contra os fungos fitopatogênicos Macrophomina phaseolina, Sclerotinia sclerotiorum e Alternaria alternata, mostrando que o óleo possui atividades antimicrobianas (MARTINS et al., 2011). Estudos de Cox et al. (2001) e Sudjana (2012) sugerem que a Melaleuca alternifolia é capaz de desnaturar proteínas alterando assim as propriedades e funções desempenhadas pela parede celular, o que ocasiona perda de componentes intracelulares e apoptose celular.

A Psidium guajava (goiabeira) é uma planta com formato de arbusto perene pertencente à família Myrtaceae, possui caule tortuoso e esgalhado medindo cerca de 7 metros, apresenta fruto globoso ou periforme, com polpa amarelada ou vermelha. É uma árvore frutífera com origem nativa das Américas Central e do Sul, cultivada em todos os países de clima tropical (MAIA et al., 2009). A goiabeira é comumente utilizada pela população por suas ações antiinfecciosas, através do consumo de chás da folha da goiabeira de polpa vermelha. Estudos mostraram que essa espécie é utilizada como planta medicinal por manifestar atividades biológicas como seu potencial analgésico, antitumoral e antimicrobiano (ALVARENGA, 2013; DESOTI, 2011). Segundo Andrade (2019), em seu estudo os extratos hidroalcoólicos e aquosos de $P$. guajava, mostraram-se eficientes sobre Staphylococcus aureus, Escherichia coli e Listeria monocytogenes, apresentando halos de inibição maior ou igual a $7 \mathrm{~mm}$ 
nas concentrações de $100 \%(\mathrm{~m} / \mathrm{v}), 75 \%(\mathrm{v} / \mathrm{v})$ e $50 \%(\mathrm{v} / \mathrm{v})$. Também foram descritos no estudo de Márquez (2010) inibição do fungo Sporothrix schenckii utilizando extratos da folha de $P$. guajava no México, diferente desse estudo que foi realizado com uma espécie endêmica do território brasileiro.

O Brasil é o país com a maior biodiversidade e, mesmo assim, ainda são escassos na literatura os estudos sobre óleos essenciais e extratos dada à infinidade de plantas medicinais que sequer foram descritas. O objetivo deste estudo foi avaliar in vitro a susceptibilidade do fungo Sporothrix schenckii aos óleos essenciais de Citrus limon e Melaleuca alternifolia e ao extrato alcóolico da folha de Psidium guajava. Essa proposta deve-se à incidência de fungos do gênero Sporothrix no Brasil, principalmente em populações de baixa renda, afetando principalmente gatos e humanos. Os dados deste trabalho poderão ser utilizados como uma proposta de tratamento alternativo utilizando óleos essenciais e extratos de plantas com finalidade medicamentosa.

\section{MATERIAL E MÉTODOS}

\section{Óleos essenciais e extrato}

O óleo essencial de limão siciliano utilizado para teste foi obtido comercialmente e pertence à empresa Derma Clean Cosmectics (Minas Gerais - Brasil), obtido da casca do limão siciliano (Citrus limon) na concentração 10\% (v/v). O óleo essencial de melaleuca utilizado para teste foi obtido em farmácia de manipulação na concentração $10 \%(\mathrm{v} / \mathrm{v})$ e utilizado nos testes sem fazer novas diluições. Para o preparo do extrato foram utilizadas as folhas de Psidium guajava (goiabeira). O extrato foi preparado seguindo o protocolo proposto pela Farmacopeia Brasileira, divulgada pela ANVISA (2018), com modificações.

As partes vegetais foram lavadas em água corrente, secas em temperatura ambiente e em seguida foram partidas manualmente em pequenos fragmentos. Após a higienização, as partes vegetais frescas foram maceradas em etanol $(70 \% \mathrm{v} / \mathrm{v})$ na proporção $5 \mathrm{~mL}$ de álcool para cada $1 \mathrm{~g}$ de planta. A solução foi armazenada em frasco âmbar e mantida em temperatura ambiente e na ausência de luz para evitar alterações no extrato. Após sete dias, o extrato foi filtrado com utilização de filtro de papel e funil, e armazenado em frasco âmbar.

\section{Cultivo microbiano}

O Sporothrix schenckii foi obtido a partir de swab de ulceração facial de animal infectado, inoculado em placa de Petri contendo Meio Sabouraud Dextrose Ágar (MSDA) sólido - preparado a partir de composto desidratado conforme determinações do fabricante, por técnica de estriamento simples e cultivado por sete dias. O microrganismo de interesse foi identificado de acordo com o Manual de Detecção e Identificação dos Fungos de Importância Médica (ANVISA, 2004) e faz parte da coleção dos microrganismos utilizados pelos pesquisadores do Laboratório de Microbiologia Aplicada da UEMG - Unidade Ibirité.

O fungo Sporothrix schenckii foi cultivado em MSDA sólido, tendo $\mathrm{pH}$ de 5,6 , por sete dias a $37^{\circ} \mathrm{C}$ para obtenção de sua forma leveduriforme. Após este período uma colônia isolada de Sporothrix schenckii foi transferida para um 
erlenmeyer contendo $50 \mathrm{~mL}$ de caldo dextrose, preparado a partir da adição de $0,5 \mathrm{~g}$ de Peptona, $2 \mathrm{~g}$ de dextrose e $50 \mathrm{~mL}$ de água destilada, possuindo $\mathrm{pH}$ 5,5

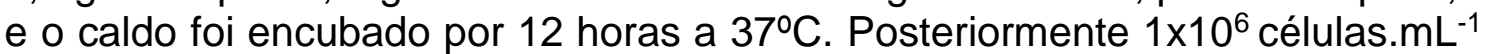
desse cultivo foram utilizadas para inocular as placas de Petri contendo Ágar Mueller-Hinton (AMH) preparado de acordo com as recomendações do fabricante, com pH de 7.2. Esse inóculo foi espalhado sobre o meio em toda a placa utilizando uma alça de Drigalsky. Sobre esse inóculo foram dispostos os discos utilizados para o teste de difusão em ágar. Após a inserção dos discos as placas foram mantidas em estufa por 24 horas a $37^{\circ} \mathrm{C}$, ao final deste período os halos de inibição produzidos foram medidos com o auxílio de paquímetro e os valores tabulados para análises estatísticas. Todo o experimento foi de forma asséptica em capela de fluxo laminar e realizado em três triplicatas.

\section{Confecção dos discos}

Os discos foram preparados de acordo com Carvalho et al. (2018). Para isso o papel filtro foi cortado em círculos, utilizando perfurador de papéis. Cada disco media $0,4 \mathrm{~mm}$ de diâmetro e foram autoclavados por 20 minutos a $121^{\circ} \mathrm{C} \mathrm{e}$ 1 atm. Posteriormente os discos foram embebidos nos extratos testes: 1- óleo essencial de Citrus limon em concentração de 10\% (v/v); 2- óleo essencial de Melaleuca alternifolia em concentração de $10 \%$ (v/v) 3- extrato da folha de Psidium guajava; 4- Itraconazol (IT) utilizado como controle positivo adquirido em farmácia e diluído para a concentração de uso de $100 \mathrm{mg} / \mathrm{mL}$; 5- álcool 70\% (v/v) como controle negativo a fim de demonstrar que a eficácia do extrato se devia às propriedades antifúngicas e não ao álcool presente no extrato.

\section{Teste de difusão em ágar}

Para a análise do teste de difusão em ágar, também denominado difusão em placas, foi utilizado o seguinte parâmetro para comparação dos halos: (i) sensíveis quando a zona de inibição é maior ou igual a $3 \mathrm{~mm}$ e inferir ao controle positivo, (ii) moderadamente sensíveis, halo maior que $2 \mathrm{~mm}$, porém menor que o controle positivo de mais de $3 \mathrm{~mm}$; e (iii) resistentes, diâmetro menor ou igual que $2 \mathrm{~mm}$. Ressalta-se que no controle positivo deve ser utilizado um fármaco padrão, como o Itraconazol, e o controle negativo o solvente utilizado para a dissolução dos extratos, no caso deste trabalho o solvente utilizado foi o álcool $70 \%$ (v/v) (OSTROSKY, 2008).

Em ágar Sabouraud foram inoculados $100 \mu \mathrm{L}$ do microrganismo (ou $1 \mathrm{x}$ $10^{6}$ células. $\mathrm{mL}^{-1}$ ) pelo método de espalhamento com auxílio de alça de Drigalsky. Posteriormente os discos embebidos com os óleos essenciais, extrato e 0 antifúngico convencional Itraconazol foram colocados sobre a placa com a ajuda de uma pinça estéril. Todo procedimento foi realizado de forma asséptica em capela de fluxo laminar. Após a inoculação, as placas foram incubadas em estufa à $37^{\circ} \mathrm{C}$ por 24 horas. Após esse período os halos observados foram medidos com auxílio de régua convencional paquímetro. 


\section{Teste estatístico}

Após obtenção dos resultados dos testes de disco de difusão foi realizada a análise estatística dos dados obtidos. Para isso foi utilizado o programa GraphPad Prism 7.0 e o teste One-Way Anova a fim de obter comparações entre o potencial inibitório dos óleos essenciais e extrato testados em comparação aos controles experimentais.

\section{Determinação da Concentração Inibitória Mínima}

O teste de Concentração Inibitória Mínima (CIM) foi realizado em capela de fluxo laminar, a partir da metodologia descrita por Carvalho (2019). Foi utilizado o método de microdiluição em microplacas de 96 poços. Os testes foram feitos em triplicata para o óleo essencial de limão siciliano, óleo essencial de melaleuca e extrato de folha de goiabeira.

Inicialmente foi depositado em cada poço das colunas 1 a 9 da placa, 100 $\mu \mathrm{L}$ de caldo Mueller Hinton estéril e em seguida, foi realizada a diluição seriada dos extratos. Foram adicionados $100 \mu \mathrm{L}$ do extrato no primeiro poço, homogeneizando a solução. Foram retirados $100 \mu \mathrm{L}$ da solução deste primeiro poço e adicionados no poço seguinte, repetindo o processo até o último poço de cada coluna. No último poço, foram descartados $100 \mu \mathrm{L}$ da solução para que houvesse em todos os poços o mesmo volume. As concentrações obtidas dos óleos essenciais e do extrato foram de $200 \mathrm{mg} \cdot \mathrm{mL}^{-1}, 100 \mathrm{mg} \cdot \mathrm{mL}^{-1}, 50 \mathrm{mg} \cdot \mathrm{mL}^{-1}$, $25 \mathrm{mg} \cdot \mathrm{mL}^{-1}, 12,5 \mathrm{mg} \cdot \mathrm{mL}^{-1}, 6,25 \mathrm{mg} \cdot \mathrm{mL}^{-1}, 3,125 \mathrm{mg} \cdot \mathrm{mL}^{-1}$ e $1,5625 \mathrm{mg} \cdot \mathrm{mL}^{-1}$. As colunas 1, 2 e 3 continham o óleo essencial de Citrus limon (limão siciliano), as colunas 4, 5 e 6 continham o óleo essencial de Melaleuca alternifolia e as colunas 7, 8 e 9 continham o extrato de $P$. guajava (goiabeira). Foram adicionados 100 $\mu \mathrm{L}$ de suspensão fúngica em cada diluição.

Como controle negativo, foi utilizado álcool $70 \%$ (v/v) diluído em uma solução com $100 \mu \mathrm{L}$ de meio Mueller Hinton estéril e $100 \mu \mathrm{L}$ de suspensão fúngica nos últimos três poços da coluna 10. Como controle positivo foi utilizado $10 \mu \mathrm{L}$ de Itraconazol adicionados à solução contendo $100 \mu \mathrm{L}$ de meio Mueller Hinton estéril e $100 \mu \mathrm{L}$ de suspensão fúngica nos últimos três poços da coluna 11. E para o controle de esterilidade foi adicionado, nos últimos três poços da coluna $12,200 \mu \mathrm{L}$ de meio Mueller Hinton estéril.

A microplaca foi incubada em estufa micológica a $37^{\circ} \mathrm{C}$ por 12 horas. Após a incubação foi feita a leitura da placa na leitora de microplacas TP Reader NM Thermo Plate no comprimento de onda de $630 \mathrm{~nm}$ e os resultados foram registrados. O programa Excel (2013) foi utilizado para análise dos dados.

\section{RESULTADOS E DISCUSSÃO}

\section{Ensaio da Atividade Antimicrobiana - Difusão em Ágar}

O microrganismo S. schenckii, que faz parte da coleção de microrganismos do Laboratório de Microbiologia Aplicada da UEMG - Ibirité foi cultivado em ágar Sabouraud Dextrose e identificado por microscopia ótica como demonstrado na Figura 1. Com a coloração foi possível confirmar as hifas 
hialinas e conidióforos com conídios implantados do fungo uiltizado neste estudo.

Figura 1 - Micélio vegetativo de $S$. schenckii corado por azul de algodão e visualizado por microscópio ótico.

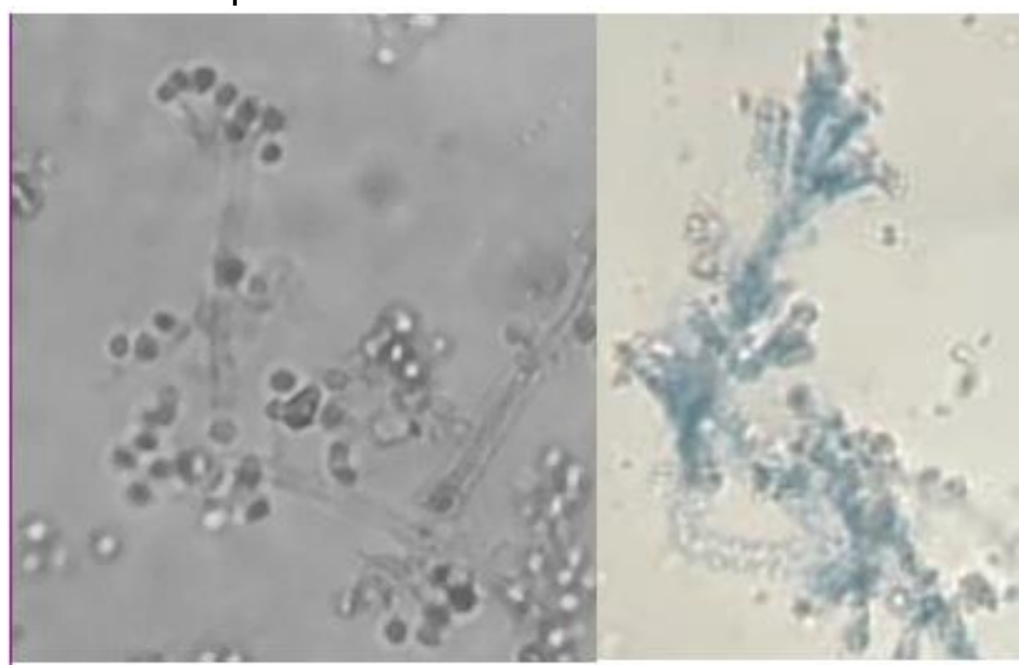

Fonte: os autores

Após o cultivo do fungo os testes realizados em difusão de ágar demonstaram que os óleos essenciais e o extrato natural utilizados apresentaram atividade como inibidores do crescimento de $S$. schenckii in vitro (Figura 2). Podem ser observados halos de inibição provocados pelos subtratos testados. Os halos medidos nos testes com óleo essencial de $C$. limon e $M$. alternifolia mediam em média $2,5 \mathrm{~cm}$ e $1,84 \mathrm{~cm}$ respectivamente. $O$ extrato de $P$. guajava apresentou uma média de $1,8 \mathrm{~cm}$. Quando comparados ao controle de Itraconazol, que foi capaz de induzir halos médios de 1,02 cm em todas as triplicatas podemos afirmar que os substratos testados apresentaram maior capacidade de inibir o crescimento microbiano do que o antifúngico comumente utilizado no tratamento contra o fungo causador da esporotricose.

Figura 2 - Ensaio da Atividade Antimicrobiana - Teste de Difusão em Ágar após 24 horas de incubação.

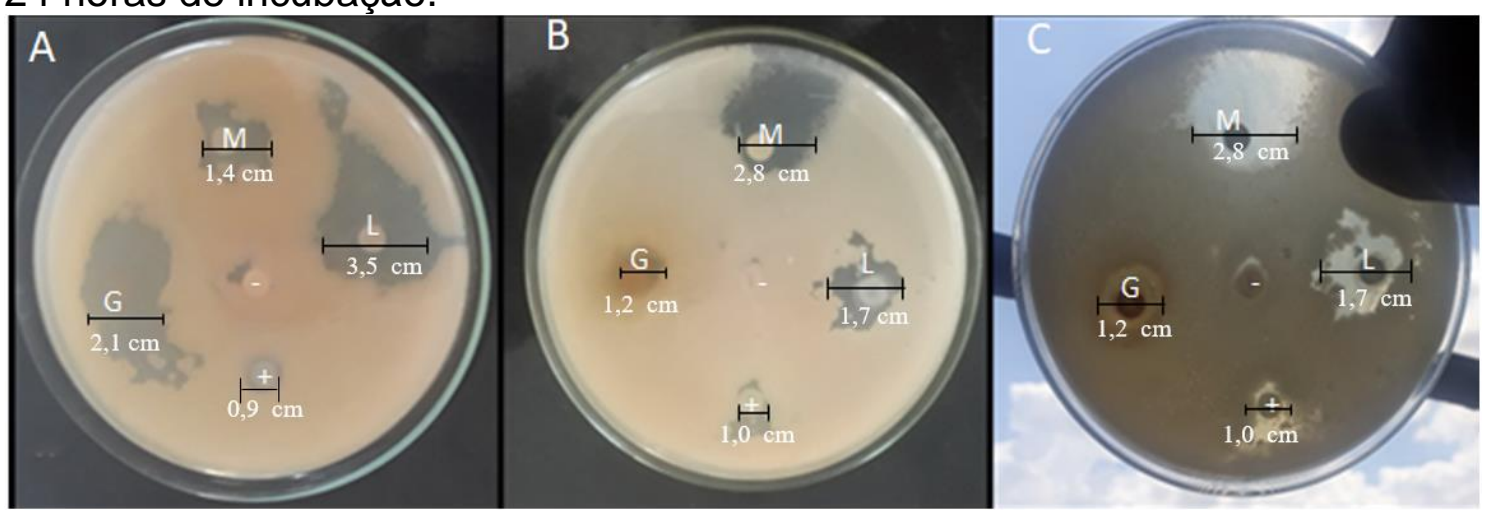

Notas: Halos de inibição medidos em centímetros para: óleo essencial de Citrus limon (limão siciliano) (L), óleo essencial de Melaleuca alternifolia (M), extrato da folha de Psidium guajava (goiabeira) (G), itraconazol (controle positivo), (+) e álcool $70 \%$ (controle negativo -). Fonte: os autores. 
Os óleos essenciais de Citrus limon (limão siciliano), Melaleuca alternifolia e o extrato de folha de Psidium guajava (goiabeira) foram capazes de inibir o crescimento de $S$. schenckii em todos os testes, sendo o óleo essencial de Citrus limon o mais eficaz, apresentando maiores halos de inibição dentre os substratos naturais testados, como pode ser observado na Figura 3, que apresenta a média dos halos verificados em todas as triplicatas. Como pode ser visto não houve diferença estatística relevante entre os substratos naturais testados.

Figura 3 - Eficácia dos óleos essenciais e do extrato testados como inibidores de Sporothrix schenckii.

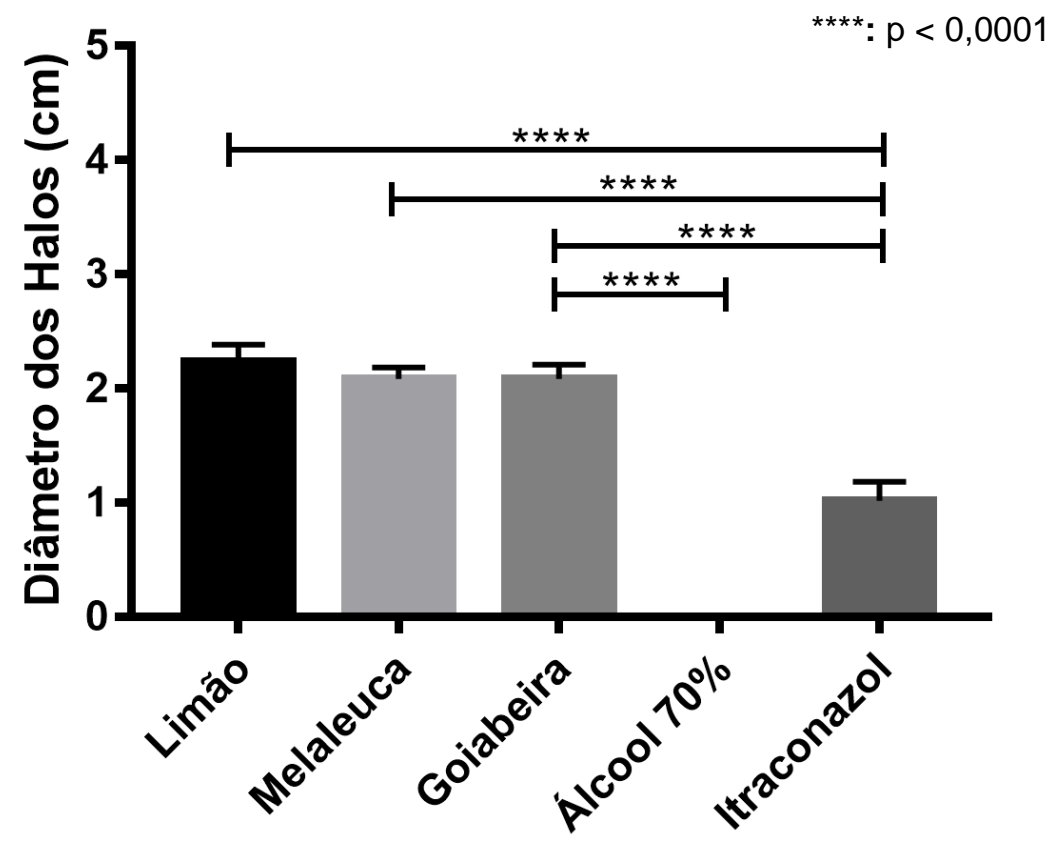

Fonte: os autores

Os dados obtidos demonstraram que o óleo essencial de Citrus limon (limão siciliano), o óleo essencial de Melaleuca alternifolia e o extrato de folha de $P$. guajava (goiabeira) foram capazes de inibir o crescimento de $S$. schenckii, com diferenças estatísticas relevantes $(p<0,0001)$ quando comparados ao controle positivo (itraconazol). Esses dados, in vitro, sugerem que tais óleos e extrato possam ser utilizados como um tratamento alternativo e de baixo custo, contra a esporotricose, uma vez que parte da população do Brasil pode não apresentar condições financeiras para obter medicamentos para tratamentos tão longos como é o caso da utilização de itraconazol para esse tipo de infecção. Além disso, os atendimentos na rede pública podem demandar muitos meses para agendamento, o que pode levar à evolução clínica da esporotricose e agravamento da infecção. Outro fato importante é que os óleos essenciais e extratos são utilizados em concentrações muito baixas, o que reduz significativamente os riscos de algum efeito colateral em animais e por isso podem não apresentar os mesmos efeitos colaterais do itraconazol, como insuficiência cardíaca e insuficiência hepática, o que ainda deve ser confirmado em futuros testes in vivo. Muitos efeitos colaterais do itraconazol contribuem para 
o abandono do tratamento clínico, agravamento dos sintomas e resistência fúngica.

Os óleos essenciais de Citrus limon (limão siciliano), Melaleuca alternifolia e o extrato da folha de Psidium guajava (goiabeira) não apontaram diferenças estatísticas quando comparados entre si $(p<0,05)$, obtendo assim a mesma eficácia na inibição. O extrato da folha de $P$. guajava (goiabeira) apresentou diferença estatística $(p<0,0001)$ quando comparado ao extrato alcoólico $70 \%$ $(\mathrm{v} / \mathrm{v})$ utilizado como controle negativo, demostrando que a inibição do crescimento ocorreu devido às propriedades vegetais do extrato e não pela presença do álcool como solvente.

Estudos de Silva (2017) mostraram que o suco puro, o extrato de folhas secas e macerado de cascas de Citrus limon possuem efeitos inibitórios sobre as bactérias $E$. coli e $S$. aureus, onde todos os extratos foram capazes de inibir um percentual entre $91,62 \%$ a $99,72 \%$ do crescimento das bactérias testadas.

Carvalho (2018) realizou uma pesquisa do efeito inibitório do óleo essencial de Melaleuca alternifolia sobre $C$. albicans, onde os resultados mostraram que o óleo essencial de melaleuca e o medicamento de uso sintético fluconazol, possuíam o mesmo padrão de inibição da $C$. albicans, apresentando halos sem qualquer diferença estatística. Demonstrando que o óleo essencial de M. alternifolia é uma alternativa ao medicamento comumente utilizado no tratamento de candidíase.

No estudo de Márquez (2010) os resultados dos efeitos do extrato da folha de $P$. guajava sobre $S$. schenckii, demonstraram que o extrato diluído em hexano, acetona e metanol, apresentaram halos de inibição de $10 \mathrm{~mm}, 10 \mathrm{~mm}$ e $16 \mathrm{~mm}$ respectivamente, provando ser eficaz no tratamento de infecções causadas por essa espécie. Esse fato reforça os dados observados no presente trabalho, onde o extrato da goiabeira demonstrou capacidade de inibir o fungo $S$. schenckii, e apresentaram halos de $2,0 \mathrm{~cm}$, sendo maiores que do estudo anteriormente citado.

Os dados obtidos com este trabalho demonstraram a eficiência em inibir $100 \%$ do crescimento fúngico para o óleo de $C$. limon na concentração mínima de 50 mg.mL-1 e $M$. alternifolia na concentração mínima de $12,5 \mathrm{mg} \cdot \mathrm{mL}^{-1} \mathrm{e}$ extrato de $P$. guajava na concentração mínima de $50 \mathrm{mg} \cdot \mathrm{mL}^{-1}$, se comparados ao Itraconazol na concentração de $100 \mathrm{mg} \cdot \mathrm{mL}^{-1}$, sendo eles uma alternativa em substituição ao Itraconazol como medicamento antifúngico.

\section{Ensaio da Concentração Inibitória Mínima (CIM)}

O Ensaio da Concentração Inibitória Mínima (CIM) apontou as concentrações dos óleos essenciais e do extrato testados, onde foram capazes de inibir $100 \%$ do crescimento fúngico de Sporothrix schenckii.

O óleo essencial de Citrus limon (limão siciliano) mostrou-se eficiente na inibição de $S$. schenckii nas concentrações de $200 \mathrm{mg} \cdot \mathrm{mL}^{-1}, 100 \mathrm{mg} \cdot \mathrm{mL}^{-1}$ e 50 mg. $\mathrm{mL}^{-1}$ (Figura 4). Nas demais concentrações houve crescimento microbiano. No entanto, foi possível verificar que o óleo essencial ainda afetou o crescimento do fungo mesmo em sua menor concentração $\left(1,5625 \mathrm{mg} \cdot \mathrm{mL}^{-1}\right)$ com inibição maior que $50 \%$ sobre o crescimento do fungo. 
Figura 4 - Ensaio da Concentração Inibitória Mínima (CIM) do óleo essencial de Citrus limon (limão siciliano) contra Sporothrix schenckii.

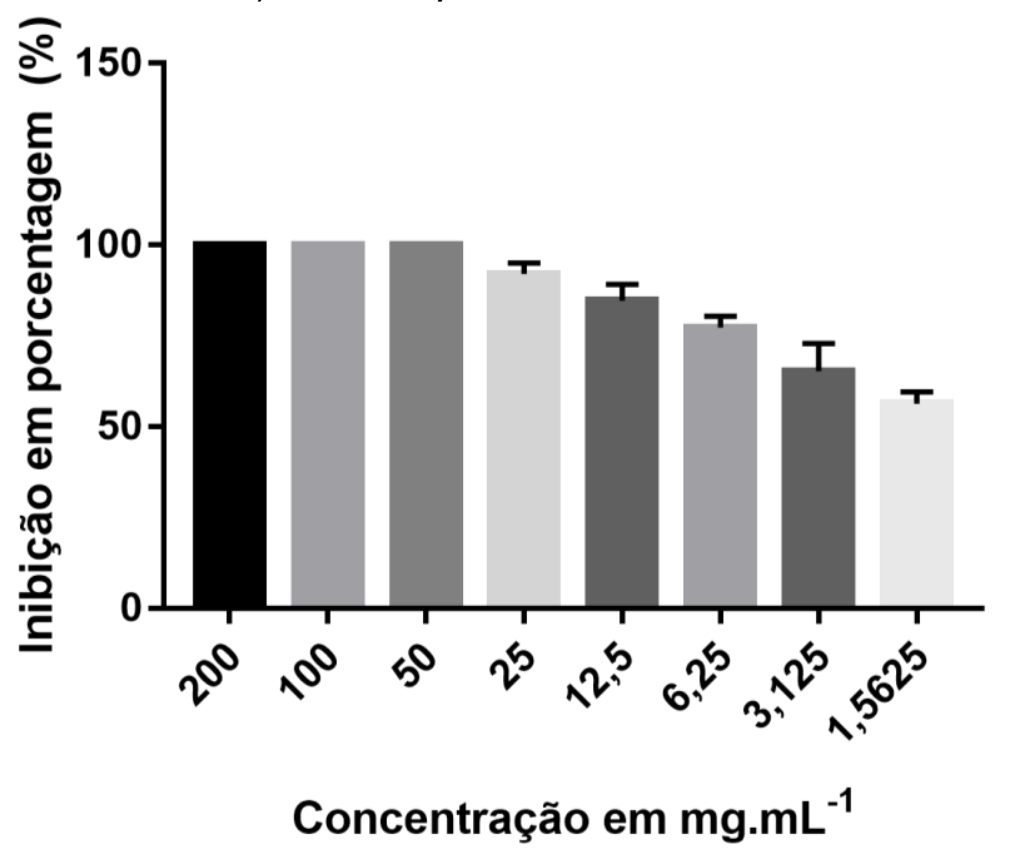

Fonte: os autores

Nos estudos de Martins (2009), foi avaliado o efeito do óleo essencial de C. limon linn sobre 22 cepas de Candida spp. A CIM foi obtida através da técnica de microdiluição onde o valor para o óleo essencial de Citrus limon foi de 0,078 e $0,156 \mathrm{mg} \cdot \mathrm{mL}^{-1}$. A observação microscópica realizada demonstrou inibição na formação de clamidoconídios e pseudo-hifas em grande parte das cepas testadas, resultado comparável ao controle positivo utilizado na pesquisa, o antifúngico sintético miconazol.

Também foram utilizadas outras espécies do gênero Citrus em estudos de Pires (2012). Eles avaliaram o efeito inibitório dos óleos essenciais da casca e da folha de Citrus limonia Osbeck (limão-cravo), Citrus aurantifolia (Chrst.) Swingle (limão-galego) e Citrus latifolia Tanaka (limão-taiti), sobre Escherichia coli, Pseudomonas. aeruginosa, Enterococcus faecalis, Streptococcus aureus, Streptococcus epidermidis, Klebsiella. pneumoniae, Salmonella sp. e Vibrio parahemolyticus. As CIM foram de 0,$5 ; 1 ; 0,25 ; 0,25 ; 0,25 ; 0,25 ; 1 ; 0,5$ e 0,25 mg. $\mathrm{mL}^{-1}$, respectivamente. Além do estudo anterior, Gomes (2011) demonstrou que os óleos essenciais de Citrus medica (cidra) e de Citrus aurantifolia (limãotaiti) foram capazes de inibir totalmente o crescimento de micélios dos fungos Fusarium oxysporum e Alternaria alternata na concentração de $2000 \mathrm{mg} \cdot \mathrm{mL}^{-1} \mathrm{e}$ para o fungo $C$. musae apenas o óleo essencial de Citrus medica (cidra) na mesma concentração, demonstrou inibição total do crescimento micelial.

Já no Ensaio da CIM do óleo essencial de Melaleuca alternifolia foi possível observar que esse óleo inibiu o crescimento de $S$. schenckii nas concentrações de $200 \mathrm{mg} \cdot \mathrm{mL}^{-1}, 100 \mathrm{mg} \cdot \mathrm{mL}^{-1}, 50 \mathrm{mg} \cdot \mathrm{mL}^{-1}, 25 \mathrm{mg} \cdot \mathrm{mL}^{-1}$ e 12,5 mg. $\mathrm{mL}^{-1}$ (Figura 5), sendo o que apresentou a menor CIM dentre os óleos e o extrato estudados, com $100 \%$ de inibição do crescimento fúngico na concentração de $12,5 \mathrm{mg} \cdot \mathrm{mL}^{1}$. Os dados apontam CIM de $12,5 \mathrm{mg} \cdot \mathrm{mL}^{-1}$ para o 
óleo essencial testado, ou seja, essa concentração já foi suficiente para inibir o crescimento do S.schenckii in vitro.

Figura 5 - Ensaio da Concentração Inibitória Mínima (CIM) do óleo essencial de Melaleuca alternifolia contra Sporothrix schenckii.

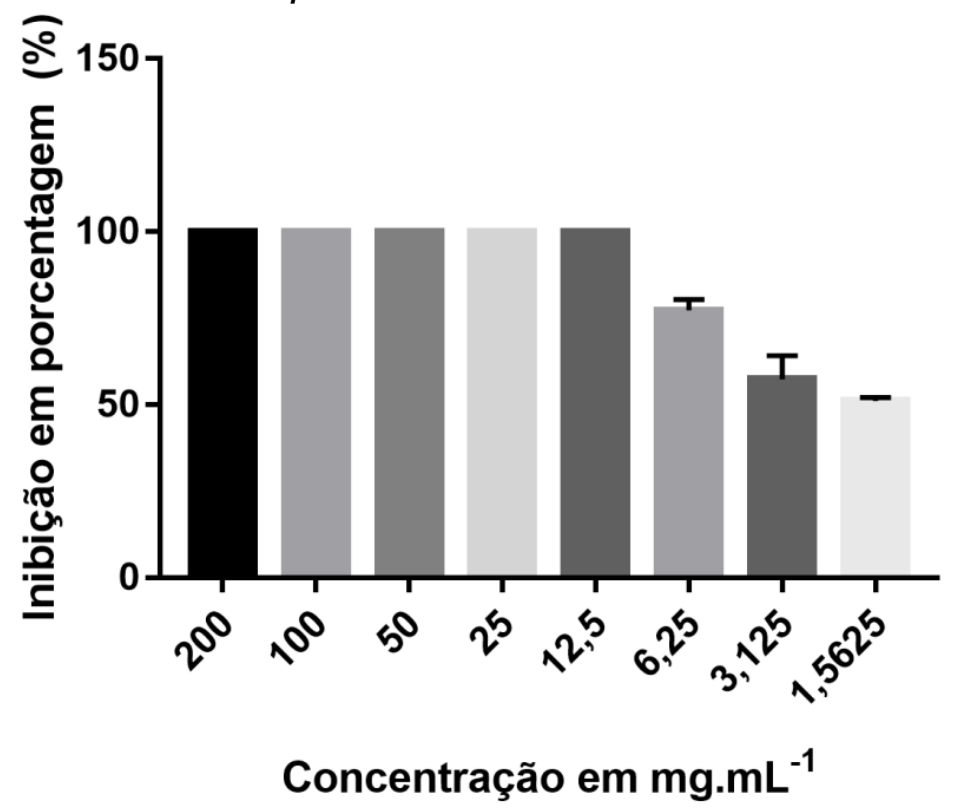

Fonte: os autores

Santos e colaboradores (2018) apresentaram dados de CIM relevantes ao avaliar o efeito inibitório do óleo de Melaleuca alternifolia frente aos fungos Fusicoccum aesculi e Colletotrichum dianesei, os quais causam doenças póscolheita em frutos da mangueira. Os testes foram realizados nas concentrações de $0,7 \mathrm{~mL} . \mathrm{L}^{-1}, 1,5 \mathrm{~mL} . \mathrm{L}^{-1}$ e 2,0 mL.L-1. Todas as concentrações do óleo essencial de Melaleuca alternifolia foram capazes de inibir significativamente 0 crescimento micelial de Fusicoccum aesculi e Colletotrichum dianesei. Não houve diferença estatística na inibição dos dois fungos nas concentrações utilizadas. Carvalho et al. (2018) em sua pesquisa, mostrou a eficácia do óleo essencial de $M$. alternifolia contra Candida albicans, onde foi observado que na concentração de $10^{-1}$ e $10^{-2}$ o óleo essencial foi capaz de inibir $100 \%$ do crescimento fúngico.

O extrato da folha de Psidium guajava (goiabeira) apresentou CIM de 200 $\mathrm{mg} \cdot \mathrm{mL}^{-1}, 100 \mathrm{mg} \cdot \mathrm{mL}^{-1}$ e $50 \mathrm{mg} \cdot \mathrm{mL}^{-1}$, sendo que as concentrações subsequentes apresentaram inibição inferior a 50\% quando comparado com as três primeiras concentrações, mostrando que não são adequadas para o tratamento de $S$. schenckii (Figura 6). Os dados apontam CIM de $50 \mathrm{mg} \cdot \mathrm{mL}^{-1}$ para o extrato testado.

Menezes (2013) utilizou o extrato alcoólico da folha de $P$. guajava para avaliar a atividade antimicrobiana contra Staphylococcus aureus e encontrou um valor de CIM de $1600 \mathrm{mg} \cdot \mathrm{mL}^{-1}$, $800 \mathrm{mg} \cdot \mathrm{mL}^{-1}$ e $400 \mathrm{mg} \cdot \mathrm{mL}^{-1}$.

Em estudos similares de Menezes et al. (2009) foi determinada que a CIM do extrato da folha de Psidium guajava possuíam os valores de 250, 125 e 62,5 $\mathrm{mg} \cdot \mathrm{mL}^{-1}$, sugerindo que o extrato apresentou potencial efeito de inibição sobre 
o crescimento de Candida albicans. Os autores também sugeriram que essa pesquisa poderá auxiliar na escolha de plantas com atividades antifúngicas para futuros trabalhos de âmbito farmacológico, uma vez que foi demonstrado o potencial inibitório da folha de goiabeira.

Figura 6 - Ensaio da Concentração Inibitória Mínima (CIM) do extrato de Psidium guajava (goiabeira) contra Sporothrix schenckii.

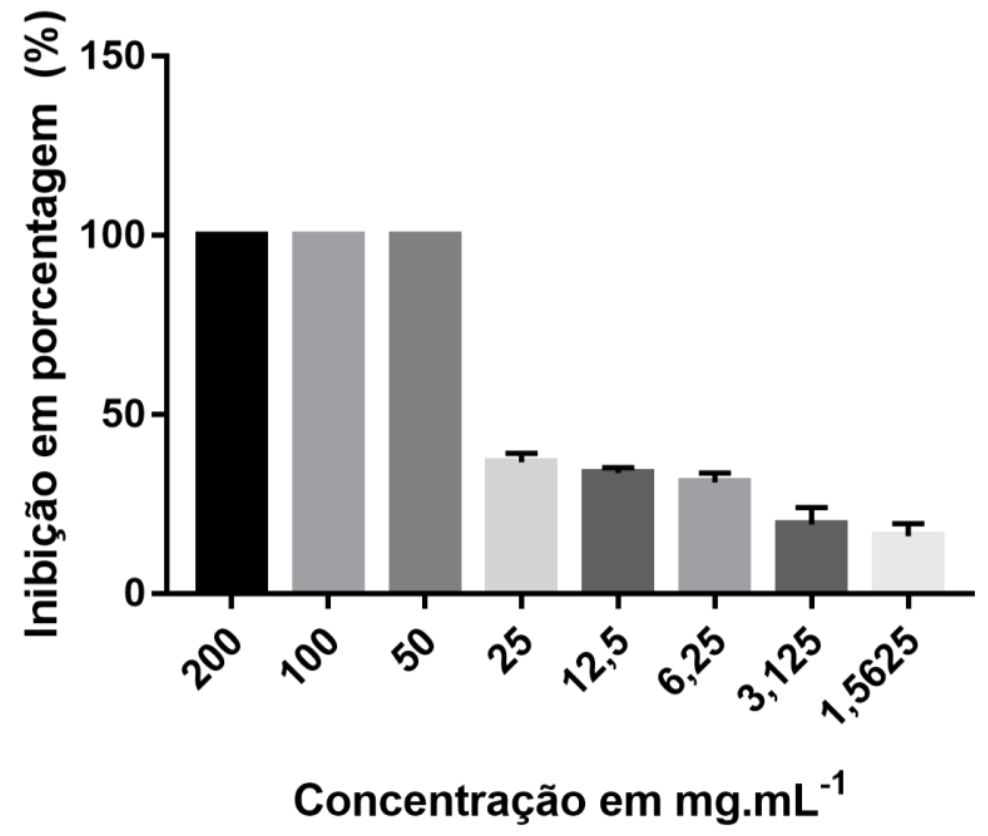

Fonte: os autores

Não foram realizados testes in vivo para verificar o efeitos dos substratos e efeitos colaterais possíveis, todavia, observados os muitos efeitos colaterais descritos na literatura advindos da administração de itraconazol e ao abandono do tratamento com esse fármaco por causa desses efeitos, a utilização de extratos naturais que funcionem como biofármacos pode ser considerada como opção de tratamento contra a esporotricose.

\section{CONCLUSÃO}

A questão norteadora dessa pesquisa foi verificar, in vitro, tratamentos alternativos, utilizando óleos essenciais e um extrato vegetal, tendo em vista que sejam de baixo custo e de fácil produção. Para isso foram utilizados os óleos essenciais de Citrus limon e Melaleuca alternifolia, e o extrato alcoólico de Psidium guajava para combater a esporotricose, tanto felina quanto humana. A relevância desse estudo deve-se ao fato do aumento progressivo de infecções causadas pelos fungos do gênero Sporothrix no Brasil, levando à esporotricose e pelos relatos de resistência fúngica ocasionado pelo uso inadequado do Itraconazol contra essas infecções ou pelo abandono do tratamento com esse fármaco que é normalmente longo e com muitos efeitos colaterais. Tais resistências tornam os fármacos disponíveis ineficazes contra a esporotricoses. Por essa razão, tratamentos utilizando fitoterápicos e plantas medicinais, surgem 
como uma alternativa para a redução da resistência microbiana e dos efeitos colaterais que esses medicamentos acarretam aos pacientes.

O presente estudo demonstrou que os óleos essenciais testados foram efetivos em inibir o crescimento de $S$. schenckii in vitro, podendo sugerir que sejam testados in vivo e futuramente utilizados como uma opção alternativa para o tratamento contra a esporotricose. O extrato de P.guajava não foi eficiente em inibir o crescimento do fungo. Em contrapartida os dois óleos essenciais testados foram capazes de reprimir o crescimento do fungo mesmo em baixas concentrações, mostrando-se mais eficazes que o Itraconazol o que representa uma vantagem para administração futura em animas.

Os dados obtidos nesse estudo fornecem uma base para que estudos in vivo sejam feitos para demonstrar a eficácia desses óleos essenciais contra a esporotricose. Também permitem sugerir que novos fármacos possam ser desenvolvidos com bases em estudos dos compostos químicos presentes nesses óleos essenciais testados e que podem ser eficazes no combate ao fungo com pouco efeito sobre as células hospedeiras. Além disso, podem sugerir que novos extratos e óleos essenciais sejam estudados no combate à esporotricose a fim de aumentar as possibilidades de biofármacos disponíveis à população para o tratamento dessa infecção. Um número maior de biofármacos eficientes contra S.schenckii pode permitir à população escolher aquele de acesso mais fácil e menos honeroso para o tratamento de gatos e humanos acometidos pela esporotricose.

\section{REFERÊNCIAS}

ANDRADE, A. P. C. et al. Ação antimicrobiana dos extratos hidroalcoólicos e aquosos da folha da goiabeira (Psidium guajava L.) no controle de Staphylococcus aureus ATTCC 27922, Escherichia coli ATTCC 25922 e Listeria monocytogenes SCOTT A. Segurança Alimentar e Nutricional, Campinas, v. 26, p. 1-7. e019028. 2019.

ANVISA, Agência Nacional de Vigilância Sanitária. Detecção e Identificação dos Fungos de Importância Médica, Mod. VII. 2004.

ANVISA, Agência Nacional de Vigilância Sanitária. Formulário de Fitoterápicos Farmacopeia Brasileira. 1ª edição, Primeiro Suplemento. ANVISA, 2018.

ALEXOPOULOS, C. J.; MIMS, C. W.; BLACKWELL, M. Introductory Mycology. 4. Ed. John Wiley \& Sons, Inc: New York, 1996.

ALVARENGA, F. Q. et al. In vivo analgesic activity, toxicity and phytochemical screening of the hydroalcoholic extract from the leaves of Psidium cattleyanum Sabine. Journal of Ethnopharmacology, v. 150, n. 1, p. 280-284, 2013.

BARROS, R. O. et al. Potencial antifúngico e modulador da resistência fúngica do óleo essencial de Cordia verbenacea DC. exposto a irradiação de microondas. Revista -ciência, v. 7, n. 1, p. 34-42, 2019. 
BERGOLD, A. M.; GEORGIADIS, S. Novidades em fármacos antifúngicos: Uma Revisão. Visão Acadêmica, Curitiba, v. 5, n. 2, p. 159-172, 2004.

BRUM, L. C. et. al. Principais dermatoses zoonoticas de cães e gatos. Clínica Veterinária, n. 69, p. 29-46, 2007.

CARVALHO, I. O. Atividade Antibacteriana de Óleos Essenciais e Cremes Dentais Fitoterápicos em Bactérias Cariogênicas. 2016. 102 f. Dissertação (Magister Scientiae). Programa de Pós-Graduação em Bioquímica Aplicada, Universidade Federal de Viçosa, Viçosa, MG. 2016.

CARVALHO, S. O.; SILVA, G. F.; CASTELUBER, M. C. F. Óleo de Melaleuca e Própolis Como Inibidor Farmacológico Natural Da Candida albicans Tratamentos Alternativos Para Candidíase. $70^{\circ}$ Reunião Anual da SBPC, UFAL, Maceió, 2018.

COSTA, C. Itraconazol para gatos: dosagem e administração. Perito Animal. 5 de fevereiro de 2019.2 Disponível em: $<$ https://www.peritoanimal.com.br/itraconazol-para-gatos-dosagem-eadministracao-22869.html\#anchor_6>. Acesso em: 30 de outubro de 2019.

COX, S. D. et al. Interactions between components of the essential oif of Melaleuca alternifolia. Journal of Applied Microbiology, v. 91, n. 3, p. 492-497, 2001.

DESOTI, V. C. et al. Triagem fitoquímica e avaliação das atividades antimicrobiana e citotóxica de plantas medicinais nativas da região oeste do estado do Paraná. Arquivos de Ciências e Saúde. v. 15, n. 1, p. 3-13, 2011.

EVERTON, G. O. et al. Atividade antioxidante e antimicrobiana das folhas e frutos de Citrus limon (L.) Burn (limão siciliano). Revista Cubana de Plantas Medicinales, v. 23, n. 4, 2018.

FALCÃO, E. M. M. et al. Hospitalizações e óbitos relacionados à esporotricose no Brasil (1992-2015). Cadernos de Saúde Pública, v. 35, n. 4, e00109218, 2019.

GOMES, M. S. Caracterização química e atividade antifúngica dos óleos essenciais de cinco espécies do gênero Citrus. 2011. 98f. (Dissertação de mestrado), Programa de Pós-Graduação em Agroquímica - Lavras, Universidade Federal de Lavras, 2011.

GUARRO J.; GENÉ J.; STCHIGEL, A. M. Developments in Fungal Taxonomy. Clinical Microbiology Reviews, v. 12, n. 3, p. 454-500, 1999.

LLORET, A. et al. Sporothricosis in cats: ABCD guidelines on prevention and management. Journal of Feline Medicine and Surgery, v. 15, n. 7, p. 619-623, 2013. 
MACEDO-SALES, P. A. et al. Diagnóstico laboratorial da esporotricose felina em amostras coletadas no estado do Rio de Janeiro, Brasil: limitações da citopatologia por imprint. Revista Pan-Amazônica de Saúde, Ananindeua, v. 9, n. 2, p. 13-19, 2018.

MADIGAN, M. T. et al. Brock Biology of Microorganisms. 14th Ed. San Francisco, CA: Benjamin Cummings/Pearson, 2015.

MAIA, R. F. et al. Estudo do efeito antimicrobiano do extrato da goiabeira (Psidium guajava LINN) sobre Staphylococcus aureus multirresistentes. Agropecuária Científica No Semi-Árido, v. 5, n. 1, p. 36-40, 2009.

MÁRQUEZ, B. P. Componentes químicos con actividad bactericida, fungicida y citotóxica de plantas de la familia Myrtaceae y Lauraceae. 2010. Tese (Doutorado em Química por Produtos Naturais), Universidad Autónoma de Nuevo León, Facultad de Ciencias Biológicas, 2010.

MARTINS, I. M. C. L. B. Avaliação da ação antifúngica de Citrus limon Linn frente a leveduras do genero Candida. 2009. Dissertação (Mestrado em Odontologia - Diagnóstico Bucal), Universidade Federal da Paraíba, 2009.

MARTINS, R. M. et al. Estudo químico e avaliação da atividade moluscicida do óleo essencial de Citrus limon L. Frente ao caramujo transmissor da esquistossomose (Biomphalaria glabrata) 58을 Congresso Brasileiro de Química, UFMA, Maranhão, 2018.

MEINERZ, A. R. M. et al. Suscetibilidade in vitro de isolados de Sporothrix schenckii frente à terbinafina e itraconazol. Revista da Sociedade Brasileira de Medicina Tropical, v. 40, n. 1, p. 60-62, 2007.

MENEZES, J. S. Ação Antimicrobiana in vitro de Psidium guajava L. Contra Staphylococcus aureus isolados de leite mastítico. Dissertação (Mestrado Programa de Pós-Graduação em Ciência Animal) - Universidade José do Rosário Vellano, Alfenas, Minas Gerais, 2013.

MENEZES, T. O. A. et al. Avaliação in vitro da atividade antifúngica de óleos essenciais e extratos de plantas da região amazônica sobre cepa de Candida albicans. Revista de Odontologia da UNESP, v. 38, n. 3, p. 184-191, 2009.

MOREIRA, L. S. et al. Estudo da resistência aos antifúngicos de leveduras isoladas de candidúrias de um hospital de médio porte. Revista Univap, v. 23, n. 43, p. 44-52, 2017.

NELSON, R. W.; COUTO, C.G. Medicina interna de pequenos animais, 3 ed. Rio de janeiro: Guanabara koogan, 1325p. 2006. 
NUNES, F. C.; ESCOSTEGUY, C. C. Esporotricose humana associada à transmissão por gato doméstico. Relato de caso e revisão de literatura. Revista Clínica Veterinária, n. 54, p. 66-68, 2005.

OJASTI, J. et. al. Informe sobre las Especies Exóticas em Venezuela, Caracas. Ministério del Ambiente y de los Recursos Naturales, 2001.

OSTROSKY, E. A. et al. Métodos Para Avaliação Da Atividade Antimicrobiana E Determinação Da Concentração Mínima Inibitória (CMI) De Plantas Medicinais. Revista Brasileira de Farmacognosia, v. 18, n. 2, p. 301-307, 2008. Disponível em: < http://www.scielo.br/pdf/rbfar/v18n2/26.pdf> Acesso em: 17 de fevereiro de 2019.

PIMENTEL, S. P. et al. Complicações do uso do Itraconazol - Revisão. Revista de Ciência Veterinária e Saúde Pública, v. 5, n. 2, p. 191-193, 2017.

PIRES, T. C; PICCOLI, R. H. Efeito inibitório de óleos essenciais do gênero Citrus sobre o crescimento de micro-organismos. Revista Instituto Adolfo Lutz. São Paulo, v. 71, n. 2, p. 259-265, 2012.

RAMOS-E-SILVA, M. et al. Sporotrichosis. Clinics in Dermatology, v. 25, n. 2, p.181-187, 2007.

RIPPON, J. W. Sporotrichosis. In: Medical Mycology. Philadelphia: WB Saunders Company, p. 325-352. 1988.

SANTOS, D. D. B. et al. Efeito de óleo de Melaleuca alternifolia na inibição de fungos pós-colheita da manga. Anais da XIII Jornada de Iniciação Científica da Embrapa Semiárido, 2018.

SANTOS, J. C. et al. Atividade antimicrobiana in vitro dos óleos essenciais de orégano, alho, cravo e limão sobre bactérias patogênicas isoladas de vôngole. Semina: Ciências Agrárias, v. 32, n. 4, p. 1557-1564, 2011.

SILVA, M. G. S. Atividade antimicrobiana, antioxidante e teor de compostos fenólicos totais de diferentes partes do limão siciliano (Citrus limon (L) Burn). 2017. 20f. Trabalho de Conclusão de Curso (Bacharel em Química Industrial), Univerisidade Federal do Maranhão, São Luiz, 2017. Disponível em: <http://hdl.handle.net/123456789/1501> Acesso em: 15 out. 2019.

SILVA, R. F. S. Revisão bibliográfica do uso do óleo de Melaleuca alternifolia no tratamento da candidíase oral. 2018. 22f. Trabalho de Conclusão de Curso (Graduação em Farmácia) - Universidade Estadual da Paraíba, Campina Grande, 2018.

SOUZA, A. F. Caracterização molecular, taxonomia polifásica, susceptibilidade a antifúngicos e extratos das sementes de Vatairea guianensis em isolados clínicos de Candida spp. na cidade de Manaus. 
2016. 112f. Tese Doutorado (Rede de Biodiversidade e Biotecnologia da Amazônia Legal, Programa de Pós-Graduação em Biodiversidade e Biotecnologia) - Universidade Federal do Amazonas, Manaus, 2016.

STEFANELLO, S. et al. Levantamento do uso de plantas medicinais na Universidade Federal do Paraná, Palotina - PR, Brasil. Revista Extensão em Foco, v. 1, n. 15, p. 15-27, 2018.

SUDJANA, A. N. et al. Candida albicans adhesion to human epithelial cells and polystryene and formation of biofilm is reduced by-inhibitory Melaleuca alternifolia (tree tee) essencial oil. Medical Mycology, v. 50, n. 8, p. 863-870, 2012.

TORTORA, G. J.; CASE, C. L.; FUNKE, B. R. Microbiologia. 12ed. Artmed Editora: Porto Alegre, 2017. 